\title{
Genome-wide identification of long noncoding RNA genes and their potential association with fecundity and virulence in rice brown planthopper, Nilaparvata lugens
}

Huamei Xiao ${ }^{1,2}$, Zhuting Yuan' ${ }^{1}$ Dianhao Guo ${ }^{1}$, Bofeng Hou' ${ }^{1}$ Chuanlin Yin ${ }^{1}$, Wenqing Zhang ${ }^{3}$ and Fei Li ${ }^{1,4^{*}}$

\begin{abstract}
Background: The functional repertoire of long noncoding RNA (IncRNA) has been characterized in several model organisms, demonstrating that IncRNA plays important roles in fundamental biological processes. However, they remain largely unidentified in most species. Understanding the characteristics and functions of IncRNA in insects would be useful for insect resources utilization and sustainable pest control.
\end{abstract}

Methods: A computational pipeline was developed to identify IncRNA genes in the rice brown planthopper, Nilaparvata lugens, a destructive rice pest causing huge yield losses. Strand specific RT-PCR were used to determine the transcription orientation of IncRNAs.

Results: In total, 2,439 IncRNA transcripts corresponding to 1,882 loci were detected from 12 whole transcriptomes (RNA-seq) datasets, including samples from high fecundity (HFP), low fecundity (LFP), I87i and C89i populations, in addition Mudgo and TN1 virulence strains. The identified N. lugens IncRNAs had low sequence similarities with other known IncRNAs. However, their structural features were similar with mammalian counterparts. N. lugens IncRNAs had shorter transcripts than protein-coding genes due to the lower exon number though their exons and introns were longer. Only $19.9 \%$ of $N$. lugens IncRNAs had multiple alternatively spliced isoforms. We observed biases in the genome location of $N$. lugens IncRNAs. More than $30 \%$ of the IncRNAs overlapped with known protein-coding genes. These IncRNAs tend to be co-expressed with their neighboring genes (Pearson correlation, $p<0.01$, T-test) and might interact with adjacent protein-coding genes. In total, 19-148 IncRNAs were specifically-expressed in the samples of HFP, LFP, Mudgo, TN1, 187i and C89i populations. Three IncRNAs specifically expressed in HFP and LFP populations overlapped with reproductive-associated genes.

Discussion: The structural features of $\mathrm{N}$. lugens IncRNAs are similar to mammalian counterparts. Coexpression and function analysis suggeste that N. lugens IncRNAs might have important functions in high fecundity and virulence adaptability.

Conclusions: This study provided the first catalog of IncRNA genes in rice brown planthopper. Gene expression and genome location analysis indicated that IncRNAs might play important roles in high fecundity and virulence adaptation in N. lugens.

Keywords: Long noncoding RNAs, RNA-seq, Genome location, Co-expression, Fecundity, Virulence

\footnotetext{
* Correspondence: lifei18@zju.edu.cn

'Department of Entomology, College of Plant protection, Nanjing Agricultural University, Nanjing 210095, China

${ }^{4}$ Ministry of Agriculture Key Lab of Agricultural Entomology, Institute of

Insect Sciences, Zhejiang University, 866 Yuhangtang Road, Hangzhou

310058, China

Full list of author information is available at the end of the article
}

\section{Biomed Central}

(C) 2015 Xiao et al. Open Access This article is distributed under the terms of the Creative Commons Attribution 4.0 International License (http://creativecommons.org/licenses/by/4.0/), which permits unrestricted use, distribution, and reproduction in any medium, provided you give appropriate credit to the original author(s) and the source, provide a link to the Creative Commons license, and indicate if changes were made. The Creative Commons Public Domain Dedication waiver (http://creativecommons.org/publicdomain/zero/1.0/) applies to the data made available in this article, unless otherwise stated. 


\section{Background}

The development of high-throughput techniques has accelerated the sequencing of insect genomes and transcriptomes, leading to the rapid accumulation of insect gene data. Currently, 156 insect genomes have been sequenced and were deposited in the NCBI genome database [1], mainly from Diptera, Lepidoptera, and Hymenoptera. Hundreds of insect transcriptomes have been submitted to the NCBI SRA database [2]. Huge amounts of insect RNA-seq data provide valuable resources to retrieve gene sequences and to estimate gene abundance by counting the read numbers [3]. However, major works on insect genome annotation and RNA-seq analysis have been limited to protein-coding genes.

Increasing evidence has showed that noncoding RNA (ncRNA) genes exist widely in the genomes of almost all organisms [4, 5]. ncRNAs are arbitrary classified into two types based on their sizes. One type is small RNAs, which are shorter than 200 nucleotides (nt), including but not limited to microRNAs (miRNAs), Piwi-interacting RNAs (piRNAs), small nucleolar RNAs (snoRNAs), and transfer RNAs (tRNAs). The other type is long noncoding RNAs (lncRNAs), with transcripts longer than 200 nt that lack protein-coding potential [6]. The lncRNAs located in the intergenic region are named as long intergenic noncoding RNAs (lincRNAs). LncRNAs with transcripts longer than $50 \mathrm{~Kb}$ are defined as very long noncoding RNAs (vlncRNAs) [7]. RNA-sequencing (RNA-seq) data are very useful resources to identify lncRNAs. Several international genome consortia, such as FANTOM, ENCODE, GETx, and modENCODE, have developed several computational approaches and identified thousands of lncRNA genes from a variety of species [8-12]. More than 9000 lincRNA genes were discovered in the human genome [8, 13-17] and $>10,000$ lincRNAs were found in the mouse genome. By analyzing 93 samples and expressed sequence datasets, 6621 lincRNAs from 4515 gene loci were identified from the pig genome [18]. In a chicken RNA-Seq dataset, Li et al. found 281 novel lincRNA genes associated with muscle development [10]. Jenkins et al. used a computational pipeline to identify lncRNAs from multiple Anopheles gambiae deep RNA-seq data, yielding 2949 lncRNA genes. These lncRNAs showed differential expression across the life stages. The secondary structures of lncRNAs are highly conserved within the Gambiae complex [19]. As an important model organism, Drosophila melanogaster has been extensively investigated for its lncRNA genes. Several efforts have identified 3193 lncRNA genes in $D$. melanogaster [20-22].

Distinct roles have been characterized for only a small subset of lncRNAs and the function of the vast majority of lncRNAs remains unknown. Several studies have shown that lncRNAs play essential roles in a wide variety of fundamental biological processes, such as cell differentiation
[16], pluripotency maintenance [23], transcription regulation [24], epigenetic regulation [25, 26], dosage compensation [27], and tumorigenesis [16]. In D. melanogaster, a yellow-achaete intergenic RNA (yar) affects sleep behavior. Yar is conserved in Drosophila species [28]. A neuralspecific lncRNA, CRG, regulates the locomotor activity and climbing ability in Drosophila [29]. These studies suggested that lncRNAs have much more important roles than expected.

The rice brown planthopper, $N$. lugens, is one of the most destructive insect pests in rice production. It directly sucks the phloem sap and transmits viruses, causing huge yield losses. The rice brown planthopper has two types of wings, long wing and short wing. The wing dimorphism is regulated by insulin receptors [30]. The long-winged brown planthopper migrates from tropical to temperate regions in summer and then back to the tropics in the autumn. In the immigrant areas, the brown planthopper population increases very quickly in one or two generations. This notorious pest has repeatedly adapted to resistant rice varieties used for pest control [31]. The high fecundity and virulence adaptation of $N$. lugens are major factors causing the high damage to rice. Insecticides are one of the most widely used methods to control rice brown planthopper. However, overuse of insecticides has resulted in resistance, resurgence, and residues. Understanding the mechanism of high fecundity and virulence adaptation is important to develop alternative pest control strategies. Here, we constructed a computational pipeline to identify lncRNAs from RNA-seq datasets of 12 samples of rice brown planthopper. We identified several lncRNAs specifically expressed in a high fecundity $N$. lugens population and found that expression patterns of lncRNAs varied between $N$. lugens strains/populations, suggesting that lncRNAs might have key roles in the fecundity and virulence of the rice brown planthopper.

\section{Results}

Identification and validation of IncRNAs in N. lugens

A computational pipeline was developed to identify lncRNA genes from the $N$. lugens transcriptome (Fig. 1). This pipeline was applied on 12 different $N$. lugens transcriptome datasets and yielded 2439 transcript isoforms corresponding to 1882 loci from $12 N$. lugens RNA-seq datasets (Additional file 1: Text file containing identified lncRNA sequences). According to genome location, we divided these lncRNA transcripts into seven types according to the guide of the HUGO Gene Nomenclature Committee (HGNC) [7]. Intergenic lncRNA transcript were named as BPHLINCxxx (xxx means number). Intronic lncRNAs, which occurred entirely within an intron were named as BPHOGSxxx-IT. BPHOGS is the official gene set of protein coding genes. LncRNAs that overlapped with a reference intron or exon on the opposite strand were named as 


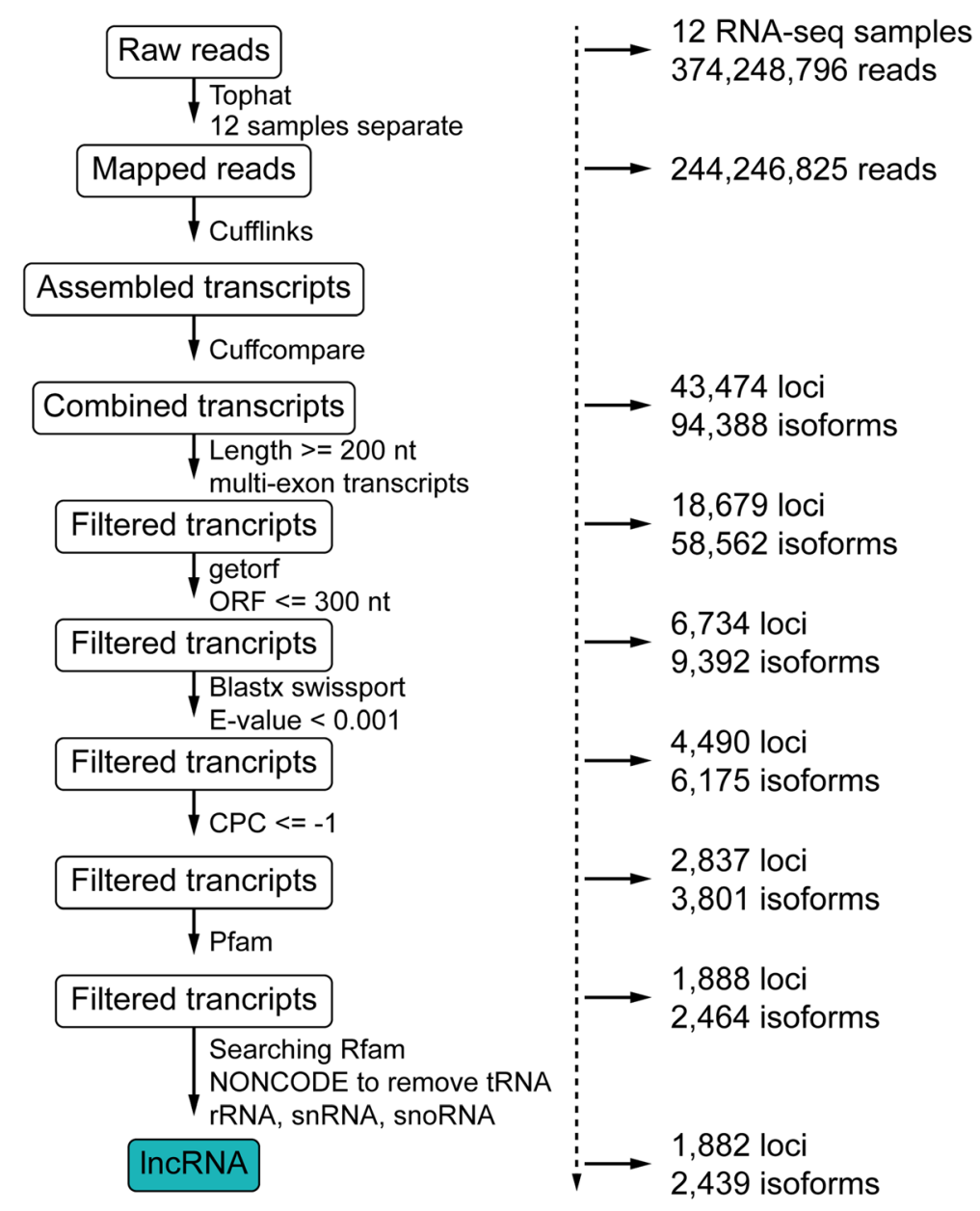

Fig. 1 The computational pipeline for identifying IncRNA genes in N. lugens from RNA-seq data

BPHOGSxxx-AS. LncRNAs that overlapped with a reference exon or splice junctions on the same strand were named as BPHOGSxxx-OT. Those IncRNA that could not be classified as any of the above types and were regarded as unclassified and were named as BPHLNC-unc.

The individual datasets were analyzed separately using the computational pipeline. In total, 948 and 1562 lncRNA genes were found in the 2-day-old adults of the LFP and HFP populations, respectively, whereas 1324 and 1563 lncRNAs were identified in the fifth instar larvae of the LFP and HFP populations. A higher number of lncRNAs (1798-2081) were discovered in the fat body, salivary gland, and antennae of the virulence-associated Mudgo and TN1 populations. 1618, 1806, and 1721 lncRNAs were found in the wild, I87i, and C89i populations, respectively (Table 1). There are several factors influencing the numbers of identified lncRNAs in the different samples. The sequencing coverage is one of the major factors. In general, the higher the coverage, the more lncRNAs could be identified (Additional file 2: Figure S1). However, there were some exceptions. The sample of 2-days-old adults of the HFP population had the lowest coverage, but 1562 lncRNA genes were identified in this sample, suggesting that lncRNA genes might have important roles in high fecundity. By contrast, the wild and I87i population had the highest coverage but they did not contain the most lncRNAs.

To confirm the reliability of the identified lncRNA genes, we selected 20 lncRNAs for RT-PCR validation. seventeen lncRNAs were successfully amplified (Additional file 3: Figure S2), suggesting that a high percentage of lncRNAs detected by this pipeline were reliable in terms of expression. The transcription orientation of these 17 IncRNAs were determined by strand-specific RT-PCR. Sixteen out of them were successfully amplified. The results demonstrated that four lncRNAs were transcribed from the sense strand whereas 12 lncRNAs from the antisense strand (Fig. 2).

\section{Structural features of IncRNAs in N. lugens}

We analyzed the structural features of lncRNA genes in $N$. lugens. Consistent with their counterparts in the mammals, $N$. lugens lncRNAs had fewer exons than protein-coding 
Table 1 The numbers of IncRNAs in individual RNA-seq datasets of different N. lugens strains/populations and in the comprehensive RNA-seq dataset

\begin{tabular}{|c|c|c|c|c|c|c|c|c|c|c|c|c|c|c|}
\hline \multirow[t]{2}{*}{ IncRNA types ${ }^{a}$} & \multicolumn{2}{|c|}{ IncRNA in 12 samples } & \multicolumn{4}{|l|}{ Fecundity $^{d}$} & \multicolumn{5}{|l|}{ Virulence } & \multicolumn{3}{|l|}{ Populations } \\
\hline & $\begin{array}{l}\text { Number of } \\
\text { IncRNA }\end{array}$ & Percentage (\%) & $\begin{array}{l}\text { LFP }^{\mathrm{b}} \\
\text { adult } 2 \mathrm{~d}\end{array}$ & $\begin{array}{l}\text { HFP }^{\mathrm{b}} \\
\text { adult } 2 \mathrm{~d}\end{array}$ & $\begin{array}{l}\text { LFP } 5^{\text {th }} \\
\text { instar larva }\end{array}$ & $\begin{array}{l}\text { HFP } 5^{\text {th }} \\
\text { instar larva }\end{array}$ & $\begin{array}{l}\text { Mudgo }^{c} \\
\text { fat body }\end{array}$ & $\begin{array}{l}\text { TN1 }{ }^{\mathrm{C}} \\
\text { fat body }\end{array}$ & $\begin{array}{l}\text { Mudgo salivary } \\
\text { gland }\end{array}$ & $\begin{array}{l}\text { TN1 salivary } \\
\text { gland }\end{array}$ & TN1 antenna & $\begin{array}{l}87 i^{c} \\
\text { population }\end{array}$ & $\begin{array}{l}\text { C89i }^{\mathrm{C}} \\
\text { population }\end{array}$ & $\begin{array}{l}\text { Wild } \\
\text { population }\end{array}$ \\
\hline Intergenic $^{1}$ & 853 & 34.97 & 344 & 534 & 440 & 536 & 694 & 682 & 739 & 727 & 569 & 603 & 560 & 496 \\
\hline Intronic $^{2}$ & 80 & 3.28 & 30 & 42 & 38 & 41 & 57 & 56 & 70 & 67 & 55 & 57 & 49 & 53 \\
\hline Intronic overlap ${ }^{3}(-)$ & 5 & 0.21 & 1 & 3 & 0 & 1 & 4 & 4 & 5 & 5 & 2 & 4 & 4 & 3 \\
\hline Exonic overlap ${ }^{4}(+)$ & 385 & 15.79 & 151 & 250 & 215 & 247 & 311 & 310 & 323 & 332 & 305 & 287 & 271 & 255 \\
\hline Exonic overlap ${ }^{5}(-)$ & 211 & 8.65 & 78 & 137 & 117 & 147 & 175 & 176 & 188 & 187 & 153 & 147 & 145 & 139 \\
\hline $\begin{array}{l}\text { Splice junction } \\
\text { overlap }^{6}\end{array}$ & 264 & 10.28 & 103 & 172 & 150 & 175 & 218 & 221 & 227 & 226 & 199 & 197 & 190 & 188 \\
\hline Unclassified $^{7}$ & 641 & 26.28 & 241 & 424 & 364 & 416 & 528 & 526 & 559 & 537 & 515 & 511 & 502 & 484 \\
\hline total & 2,439 & 100 & 948 & 1,562 & 1,324 & 1,563 & 1,987 & 1,975 & 2,111 & 2,081 & 1,798 & 1,806 & 1,721 & 1,618 \\
\hline
\end{tabular}

ancRNA types: 1) Intergenic transcript, 2) falling entirely within a reference intron, 3) overlaps with a reference intron on the opposite strand, 4) overlaps with a reference exon, 5) overlaps with a reference exon on the opposite strand, 6) At least one splice junction is shared with a reference transcript, 7) Unclassified

${ }^{\mathrm{b}}$ LFP low fecundity population, HFP high fecundity population

'TN1: avirulent Taichung Native 1 host strain, Mudgo: virulent (carrying the resistance gene bph1) host strain, 187i lzumo87 strain, C89i: Chikugo89 strain

${ }^{\mathrm{d}}$ Based on the analysis of the 12 RNA-seq datasets together using the computational pipeline developed 


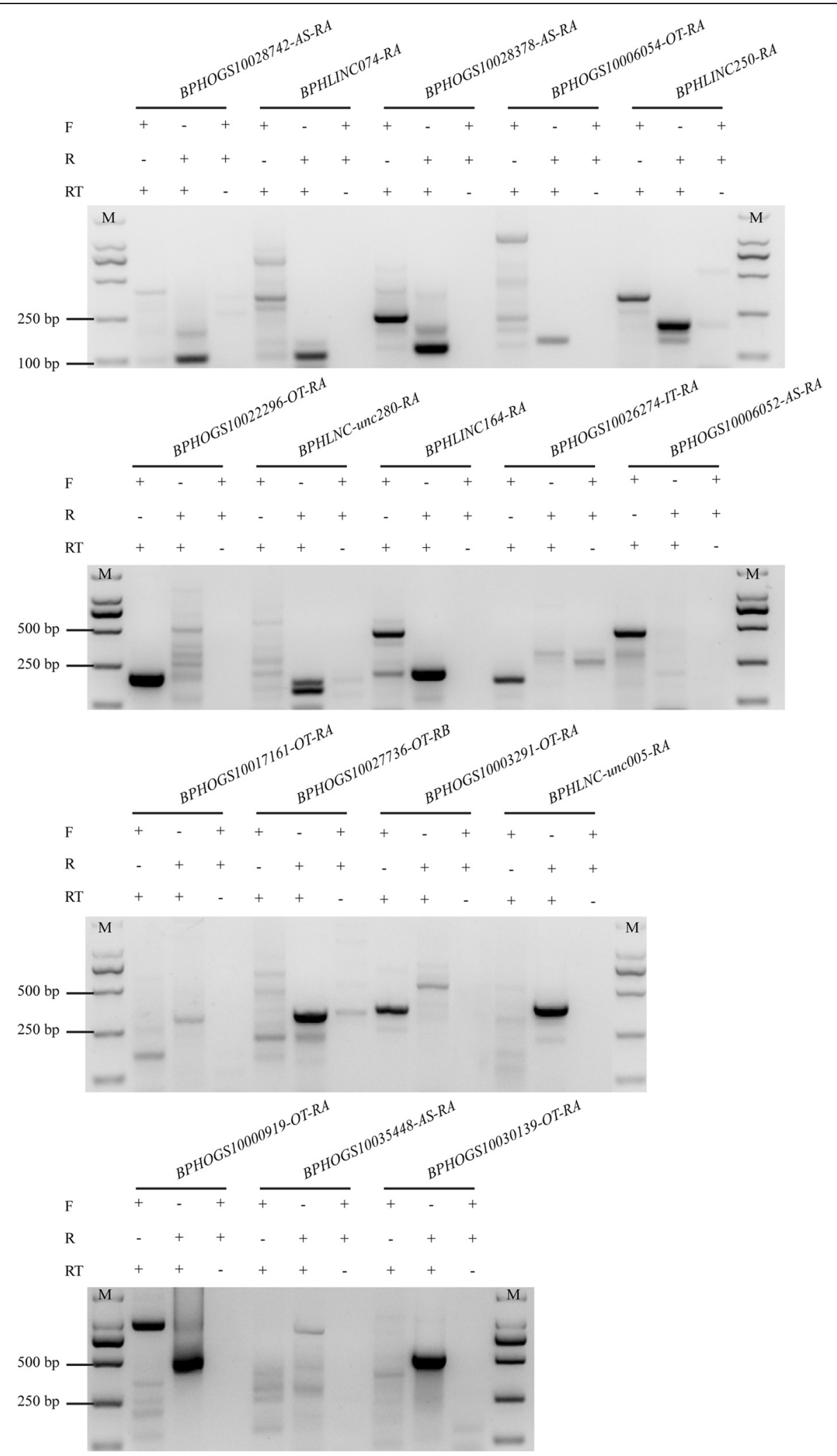

Fig. 2 (See legend on next page.) 
(See figure on previous page.)

Fig. 2 Strand-specific PCR of 17 randomly selected IncRNAs to determine the transcription orientation. BPHOGS10035448-AS-RA was not amplified with a correct band. So, 16 IncRNAs were successfully amplified and confirmed by sequencing (see Figure S2 for RT-PCR validation). The results indicated that 12 IncRNA transcribed from the antisense strand, and four from the sense strand. F: forward primer (sense); R: reverse primer (antisense); RT:

reverse transcriptase

genes (Fig. 3a). $77.9 \%$ of $N$. lugens lncRNAs had only two exons, which is nearly twice the ratio of $40.4 \%$ observed in protein-coding genes. By contrast, only $4.34 \%$ of lncRNA genes had four exons, which is significantly lower than $11.70 \%$ of protein-coding genes. The average transcript length of $N$. lugens $\operatorname{lncRNAs}$ was 841 bp whereas that of protein-coding genes was 1106 bp (Fig. 3b). Interestingly,
lncRNA genes had longer exons (363 bp on average) and longer introns (7792 bp on average) than protein-coding genes (250 bp exons and 2583 bp introns, Fig. 3c and d). However, lncRNAs had shorter transcripts than proteincoding genes because of the lower number of exons.

Only $19.9 \%$ of $N$. lugens lncRNA genes had alternative splicing (AS) (Additional file 4: Figure S3), suggesting
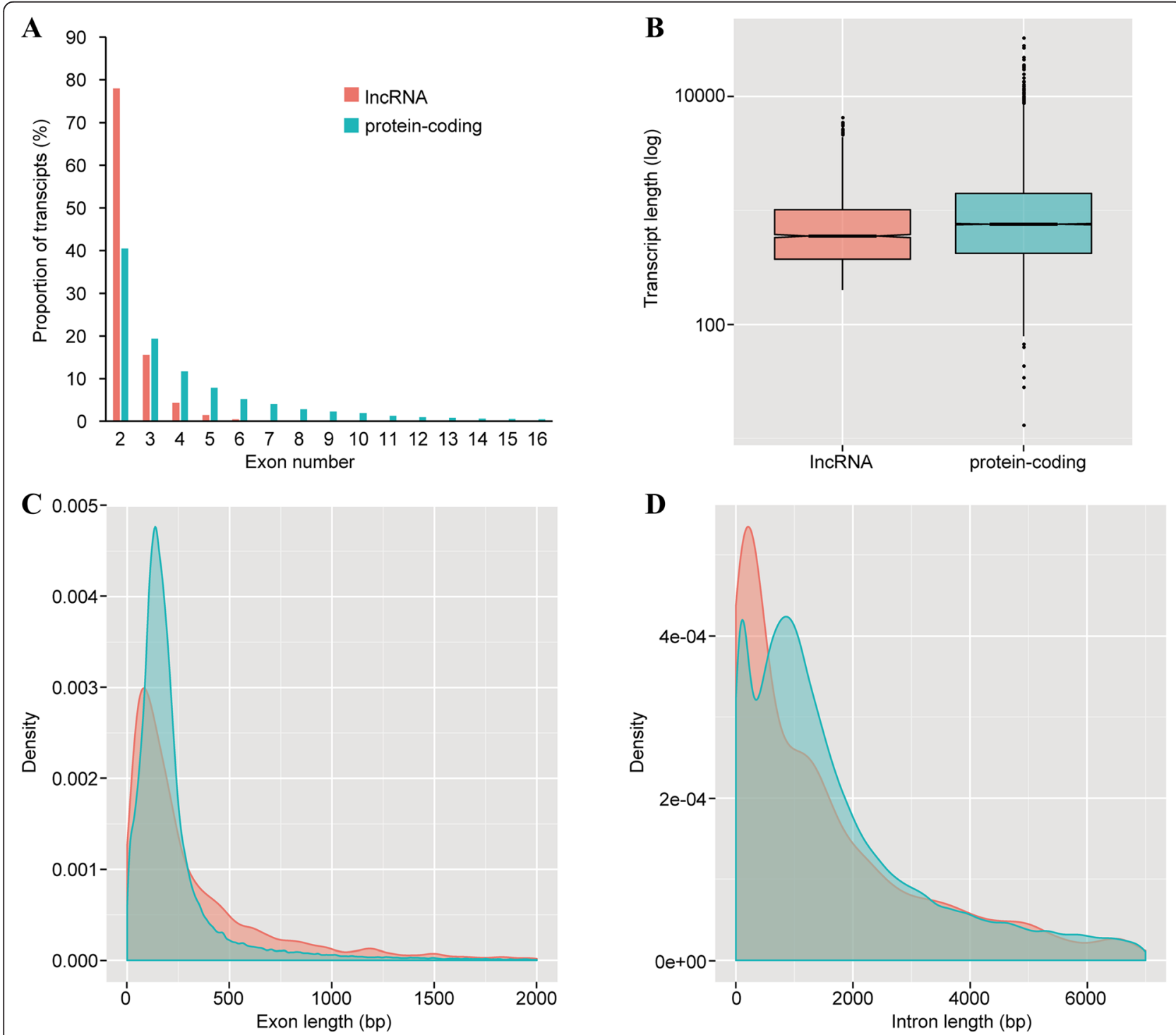

Fig. 3 Structural gene features of N. lugens IncRNA genes. a The number of exons per transcript of IncRNAs and protein-coding genes. The majority of IncRNAs have only two exons. b The transcript lengths of IncRNA and protein-coding gene. On average, IncRNAs have short transcripts. $\mathbf{c}$ The distribution of exon sizes of IncRNA and protein-coding genes. $\mathbf{d}$ The distribution of intron sizes of IncRNA and protein-coding genes. The density in Y-axis means the area under the curve of a density function represents the probability of getting an $\mathrm{x}$ value between a range of $\mathrm{x}$ values. Red: IncRNA, green: protein-coding genes 
that AS is not prevalent in lncRNA genes. However, there were some exceptions. Some lncRNAs showed abundant alternative splicing events. BPHOGS10002343$O T$ and BPHOGS10000007-OT had 11 isoforms, and BPHLNC-unc241 had ten isoforms (Fig. 4). We selected $B P H L N C-u n c 241$ to validate alternatively spliced transcripts. Isoform-specific primers of ten alternatively spliced transcripts were designed. Out of them, five isoforms were successfully amplified and were confirmed by sequencing (Fig. 5a). Though there was a band in the lane of variant J, the PCR product size was not correct and the sequencing result was not as expected. Possibly because of spatiotemporal expression of alternatively spliced isoforms, other four isoforms were not detected. We selected the 3rd, 4th, 5th instar nymph and adult to study the expression of five isoforms. Semi-quantitative PCR indicated that BPHLNC-unc241-RA and BPHLNCunc241-RI were highly expressed in the 3rd and the 4th instar nymph but lowly in other stages. BPHLNC-unc241$R C$ was expressed only in the 3rd and 4th instar whereas $B P H L N C-u n c 241-R H$ only in the 4th instar. The mRNA abundance of BPHLNC-unc241-RG was high in all samples except the 3rd instar nymph (Fig. 5b). These results suggest that alternatively spliced isoforms of BPHLNCunc241- $R$ have different expression profiles and might have differential functions during development.

\section{Specifically-expressed and differentially-expressed IncRNAs} We estimated the transcript abundance of lncRNAs using raw reads of all $12 N$. lugens RNA-Seq datasets.
The results indicated that most lncRNAs were expressed in almost all $N$. lugens transcriptomes (Fig. 6). Interestingly, we found that the number of specifically expressed IncRNAs was higher than that of differentially expressed lncRNAs (Additional file 5: Table S1). In total, 19-148 lncRNAs were specifically-expressed whereas $0-10$ lncRNAs were differentially-expressed in LFP, HFP, TN1, Mudgo, I87i and C89i population (Additional files 6, 7, 8, 9, 10, 11, 12 and 13: Table S2, S3, S4, S5, S6, S7, S8 and S9). There were 146 specifically-expressed IncRNAs and ten differentially highly-expressed lncRNAs in the adult of HFP population. One hundred and forty-eight specifically-expressed and two highly-expressed lncRNAs were found in the fifth instar nymph of HFP population. In the adult and the fifth instar larvae of the LFP population, 58 and 76 lncRNAs were specifically-expressed while three and one lncRNAs were highly-expressed. In the fat body and salivary gland of the Mudgo and TN1 populations, there were only 21-42 specifically-expressed lncRNAs and 0-4 differentially-expressed lncRNAs. The high numbers of specifically-expressed lncRNAs in LFP and HFP populations suggested that lncRNAs might play key roles in the fecundity of $N$. lugens.

\section{LncRNAs associated with fecundity}

It has been reported that lncRNAs tend to be coexpressed with the overlapping genes or adjacent genes by sharing a same primary transcript. Some lncRNAs interact with overlapping or adjacent genes by chromosome modeling [32]. We found that $30 \%$ of $N$. lugens lncRNA genes

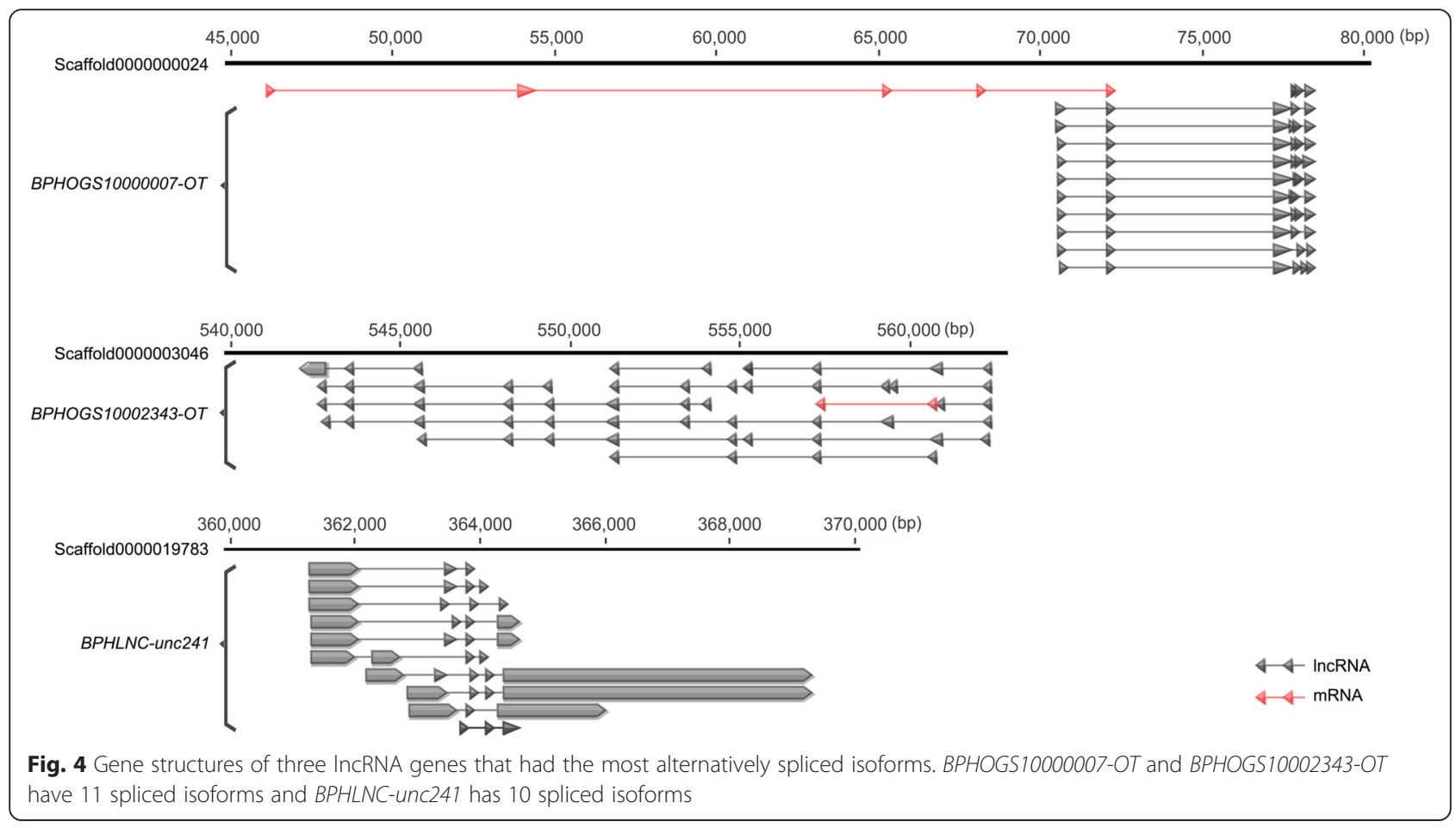




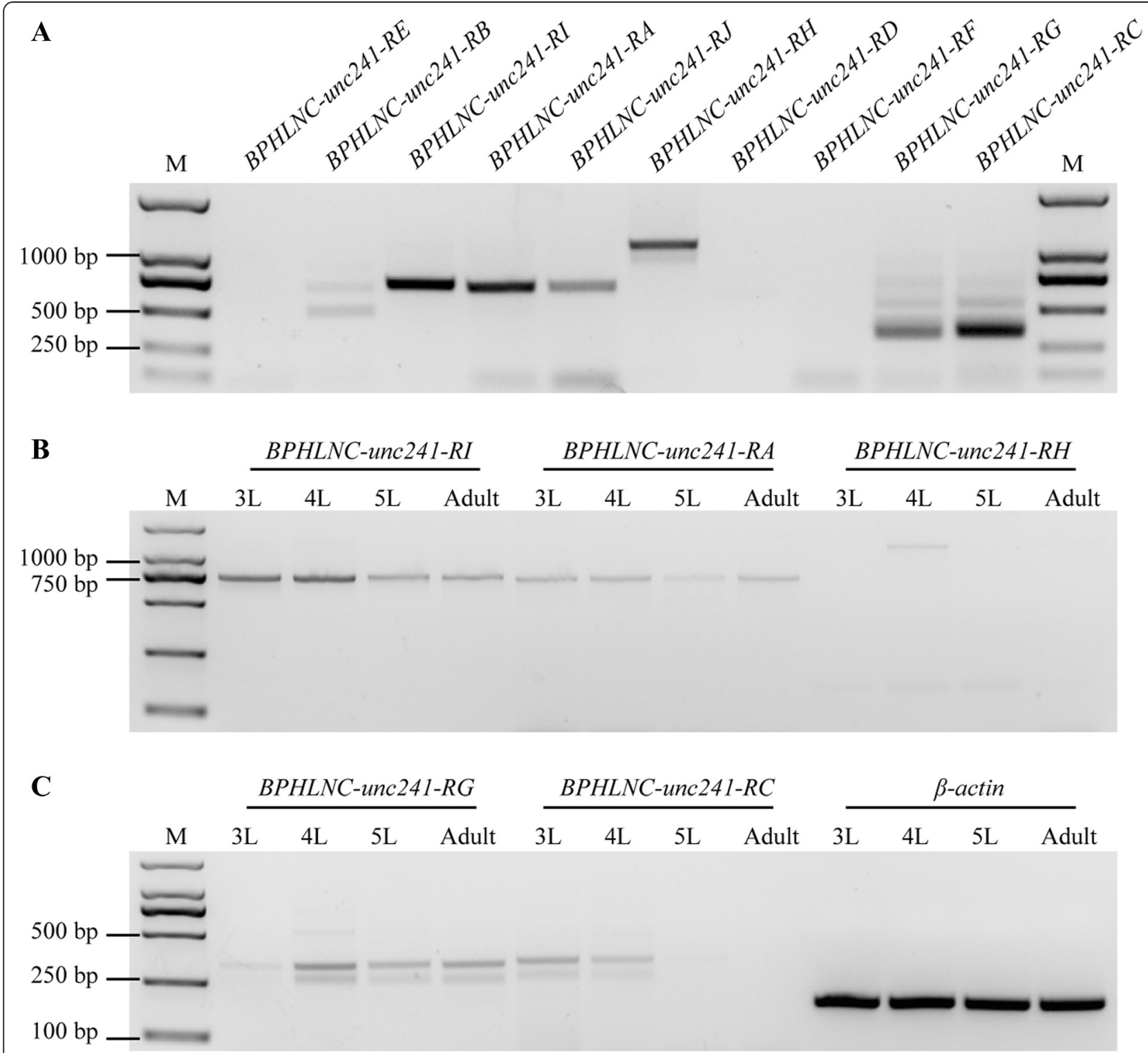

Fig. 5 RT-PCR validation of alternatively spliced transcripts of BPHLNC-unc241. Isoform-specific primers were designed for ten isoforms. Five of them were successfully amplified followed by sequencing. The PCR product size and the sequencing result of variant J was not as expect (a). The expressions of five isoforms in the third instar to fifth instar nymph and adult were measured, suggesting transcript variants vary in their expression profiles (b,c)

overlapped with known protein-coding genes (Fig. 7). In different samples, there were a number of lncRNAs located within $<5 \mathrm{~Kb}$ of protein-coding genes (Table 2). The Pearson correlation $r$ of transcripts abundance between lncRNAs and their adjacent protein-coding genes was 0.1 , which was significantly higher than the Pearson correlation $\mathrm{r}(-0.03)$ between lncRNAs and randomly selected coding genes $(P<0.01, T$-test, Fig. 8$)$, suggesting that lncRNAs tend to be co-expressed with their adjacent genes. Interestingly, five lncRNA genes overlapped with two protein-coding genes (Fig. 9).

In the HFP population, there were 6992 protein-coding genes that were co-expressed with lncRNAs, among which
46 protein-coding genes involve in energy metabolism. In the LFP population, there were 7089 protein-coding genes that were co-expressed with lncRNAs, among which 48 protein-coding genes involve in energy metabolism. The protein coding genes associated with energy metabolisms were not located adjacently or overlapped with any lncRNAs.

We found that three IncRNA genes overlapped with reproduction-associated genes (Fig. 10). Two lncRNAs (BPHOGS10035598-OT and BPHOGS100007976-OT) were specifically-expressed in the fifth instar nymph of the HFP population. One lncRNA (BPHOGS10005591-OT2) was specifically-expressed in the fifth instar nymph of the LFP 

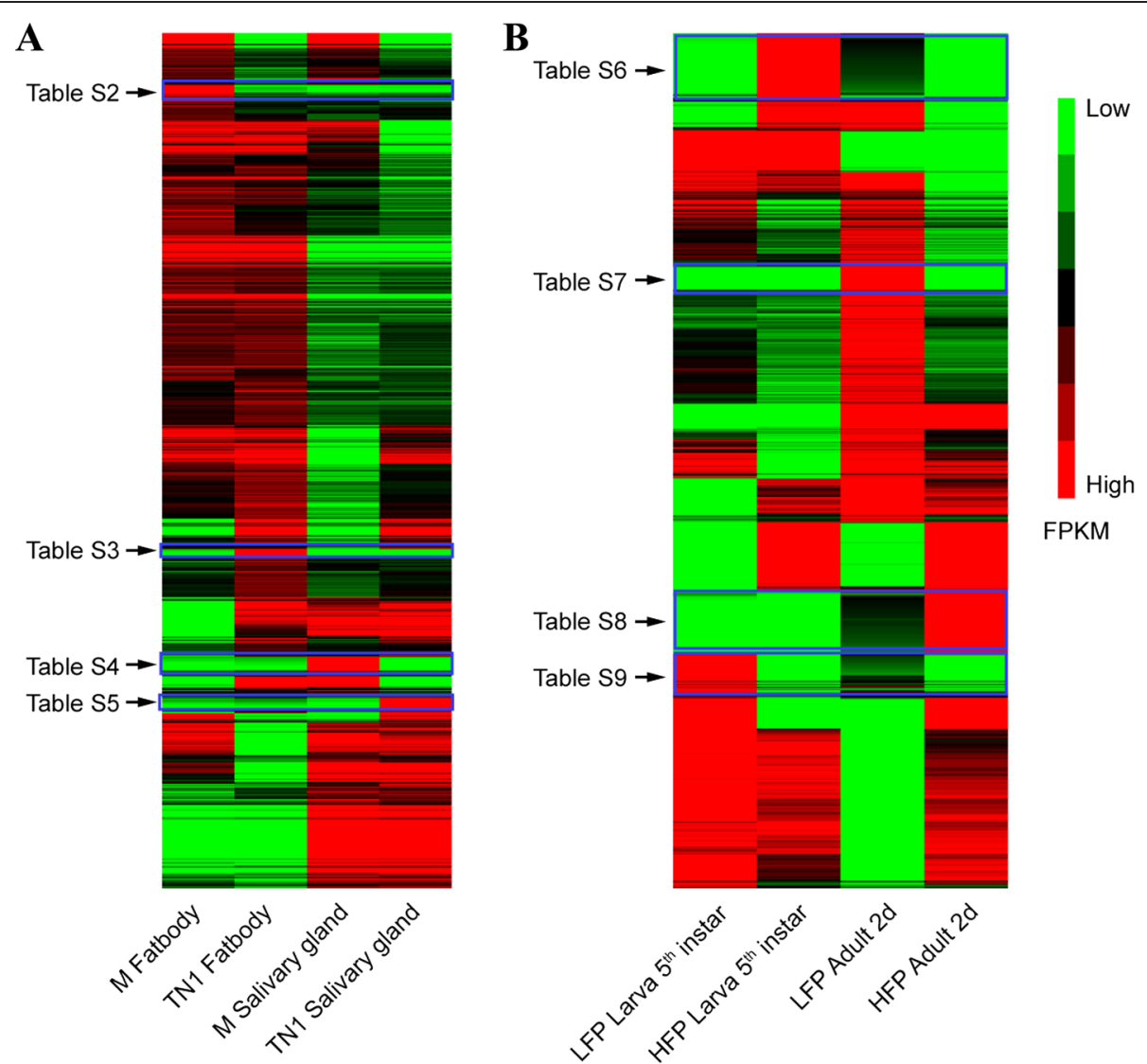

Fig. 6 The heatmap of the IncRNA expression patterns in virulent and fecund populations. a Expression profile changes of IncRNA transcripts across the fat body and salivary gland in the Mudgo and TN1 populations. $\mathbf{b}$ Hierarchical clustering of expressional abundance of IncRNA transcripts in the nymph and adult of the HFP and LFP population. The IncRNAs showing tissue specific expression in the Mudgo and TN1 populations are listed in Additional file 6, 7, 8 and 9: Tables S2, S3, S4 and S5. The IncRNAs specifically expressed in the fifth instar nymph and adult were listed in Additional file 10,11,12 and 13: Tables S6, S7, S8 and S9

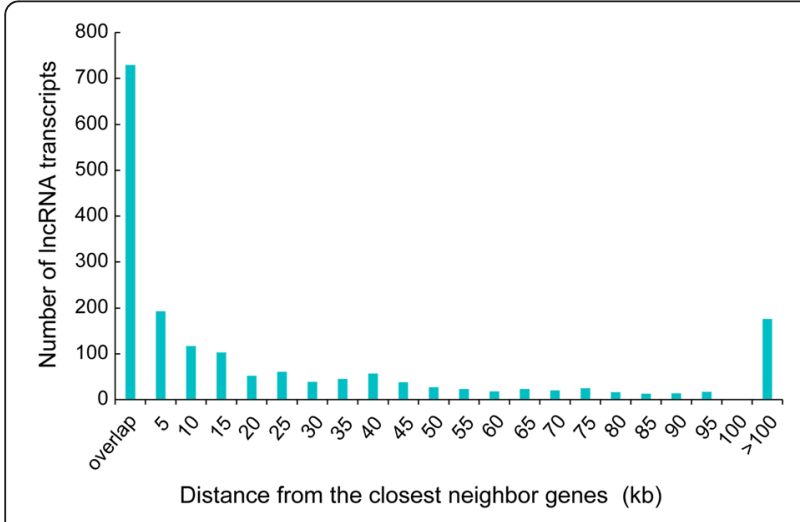

Fig. 7 The genome location of IncRNA in N. lugens, demonstrating that IncRNAs tend to located adjacently to protein-coding genes $(<5 \mathrm{~Kb})$. A high number of IncRNAs overlapped with proteincoding genes population. BPHOGS10005591-OT2 overlapped with the glucose dehydrogenase $(G L D)$ gene at the 3 ' region comprising $2365 \mathrm{bp}$. GLD is essential for sperm storage in adult female of D. melanogaster. BPHOGS100007976-OT was located at the 5 -upstream of the gastrulation defective gene and overlapped with this gene for $3354 \mathrm{bp}$. The gastrulation defective gene encodes a serine protease that cleaves and activates protein SNAKE. The activated SNAKE cleaves and activates protein EASTER. This series of activations controls the embryo dorsoventral polarity. BPHOGS10035598-OT overlapped with the $\mathrm{N}$-acetylgalactosaminytransferase 7 gene (GALNT7) at its 5 '-end for $878 \mathrm{bp}$. GALNT7 participates in reproductive regulation in $D$. melanogaster.

We carried out RT-PCR to confirm the transcription of three lncRNAs and their adjacent protein-coding genes using a wild population. The different combinations of primer-pairs were used to examine the transcripts. The results suggested that the identified OT-type of lncRNAs were not the artifacts of full-length coding sequences. 
Table 2 Specifically expressed N. lugens IncRNA in varied RNA-seq datasets

\begin{tabular}{|c|c|c|c|c|}
\hline \multirow[t]{2}{*}{ Samples } & \multicolumn{4}{|c|}{$\begin{array}{l}\text { Specific expressed IncRNA distribution according to the distance with the closest gene (IncRNA transcript number/closes } \\
\text { gene number) }\end{array}$} \\
\hline & overlap & $<5 k$ & $<10 k$ & $>10 k$ \\
\hline HFP adult $2 \mathrm{~d}$ & $36 / 33$ & $10 / 9$ & $9 / 8$ & $41 / 54$ \\
\hline LFP adult $2 \mathrm{~d}$ & $17 / 17$ & $3 / 4$ & $4 / 4$ & $9 / 9$ \\
\hline HFP $5^{\text {th }}$ instar larva & $37 / 36$ & $20 / 22$ & $8 / 9$ & $44 / 56$ \\
\hline LFP $5^{\text {th }}$ instar larva & $19 / 18$ & $11 / 11$ & $6 / 6$ & $22 / 25$ \\
\hline Mudgo fat body & $6 / 6$ & $5 / 5$ & $1 / 1$ & $7 / 7$ \\
\hline TN1 fat body & $8 / 8$ & $3 / 3$ & $1 / 1$ & $3 / 5$ \\
\hline Mudgo salivary gland & $7 / 7$ & $4 / 5$ & $5 / 5$ & $11 / 18$ \\
\hline TN1 salivary gland & $8 / 8$ & $2 / 2$ & $1 / 1$ & $7 / 9$ \\
\hline
\end{tabular}

BPHOGS10005591-OT2 and BPHOGS10007976-OT were transcribed independently from there adjacent proteincoding genes whereas BPHOGS10035598-OT might share a same transcript with its adjacent protein-coding gene BPHOGS10035598 (Fig. 11).

\section{Discussion}

We identified 2439 lncRNA transcripts corresponding to 1882 loci from $12 \mathrm{~N}$. lugens RNA-seq datasets including four transcriptome datasets of LFP or HFP fecundity strains, five transcriptomes from the fat body, salivary

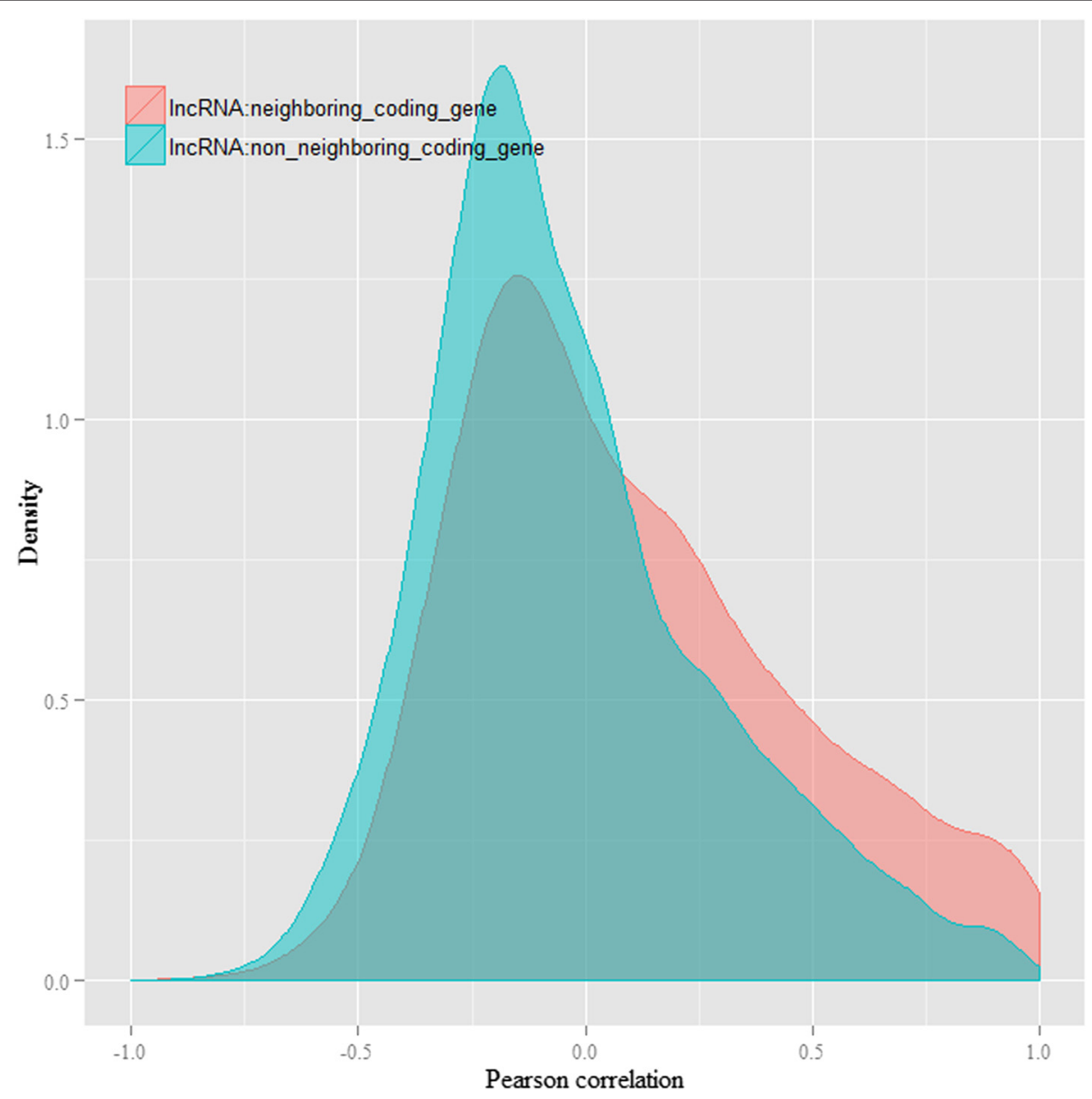

Fig. 8 The distribution of Pearson product-moment correlation coefficient between IncRNA and protein-coding genes. IncRNAs had higher coefficients with their neighboring protein-coding genes than with non-neighboring genes, suggesting that IncRNAs tends to be co-expressed with neighboring genes. The density in Y-axis means the area under the curve of a density function represents the probability of getting an $\mathrm{x}$ value between a range of $x$ values 


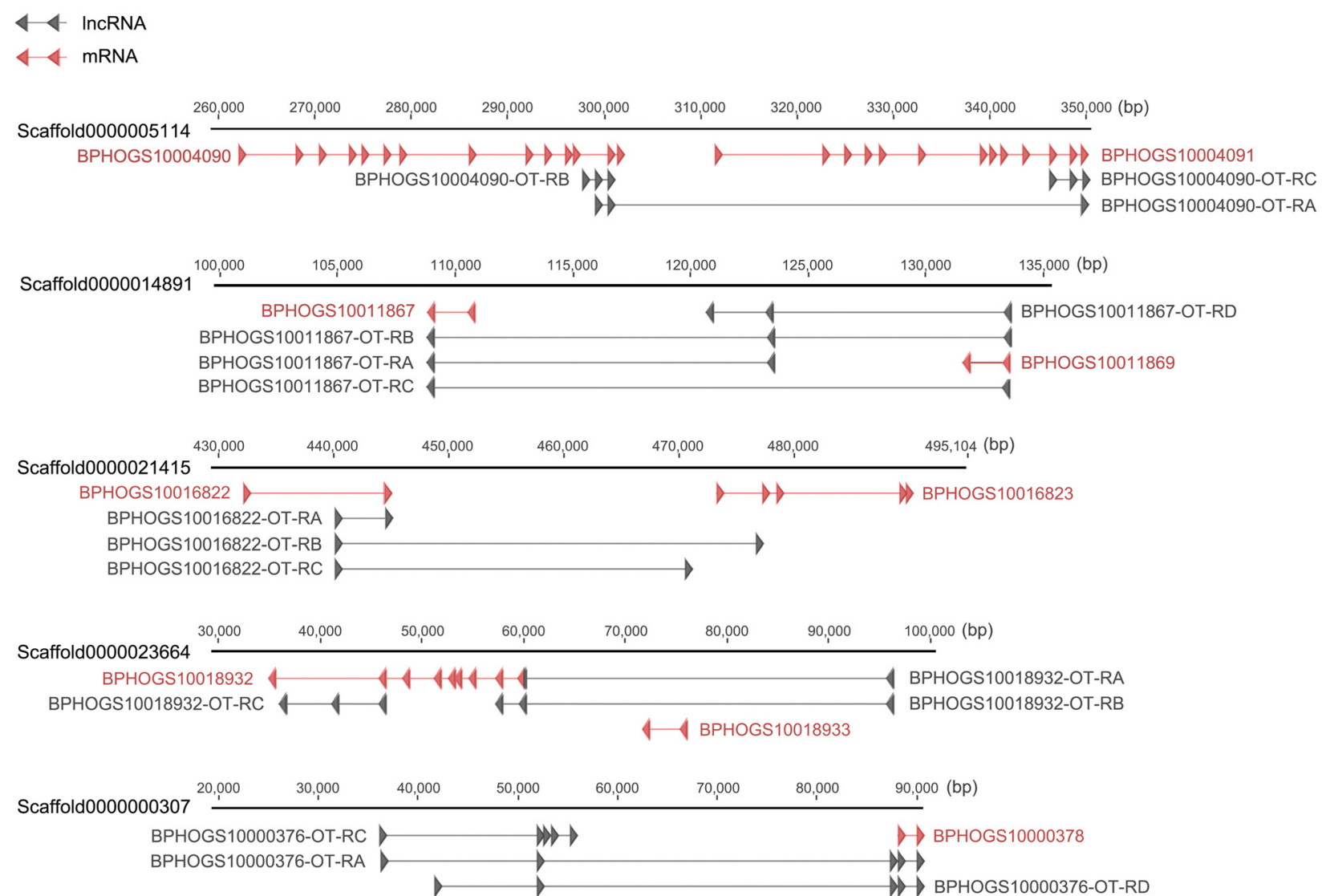

Fig. 9 Gene structures of five IncRNA genes. These IncRNA genes had multiple isoforms and overlapped with two adjacent protein-coding genes

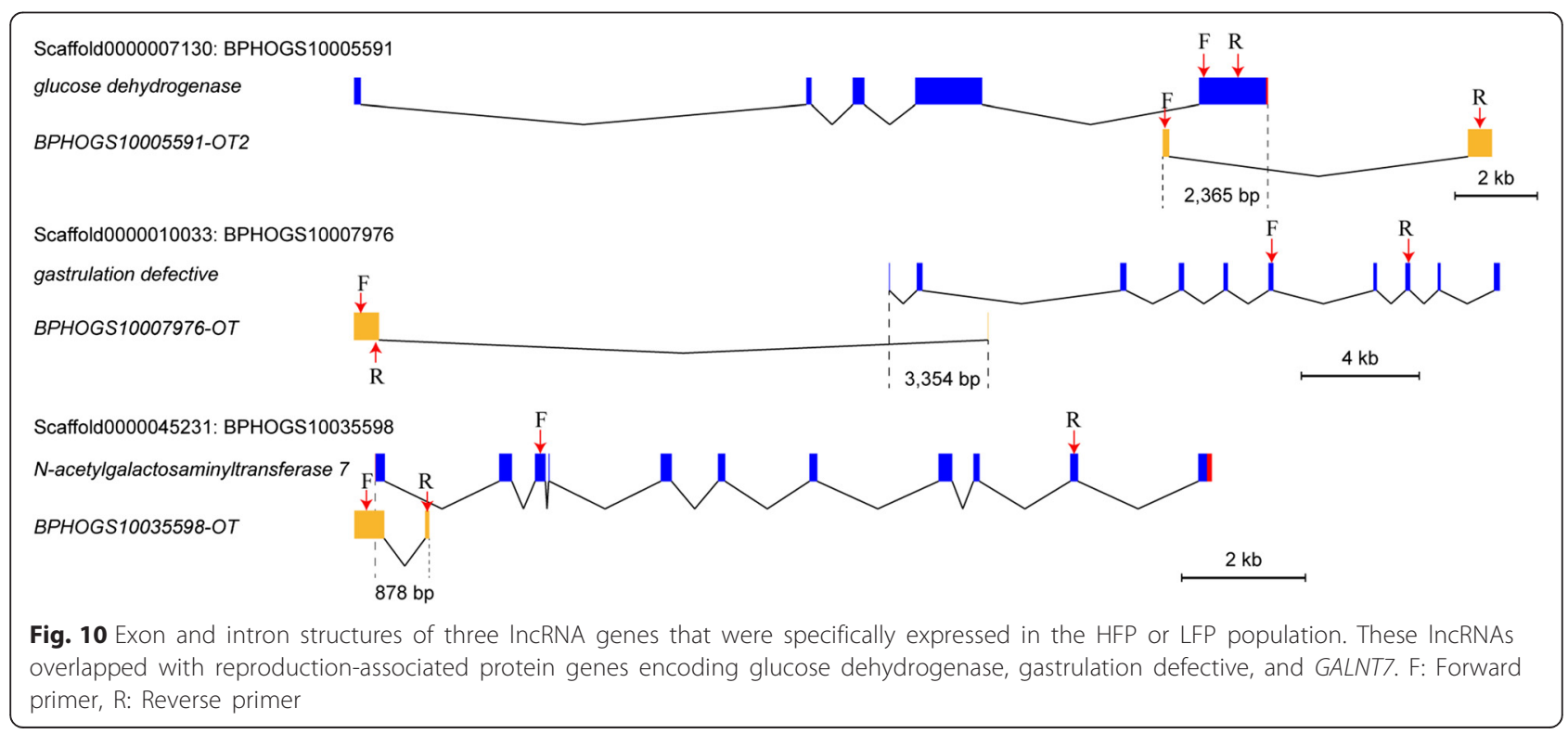




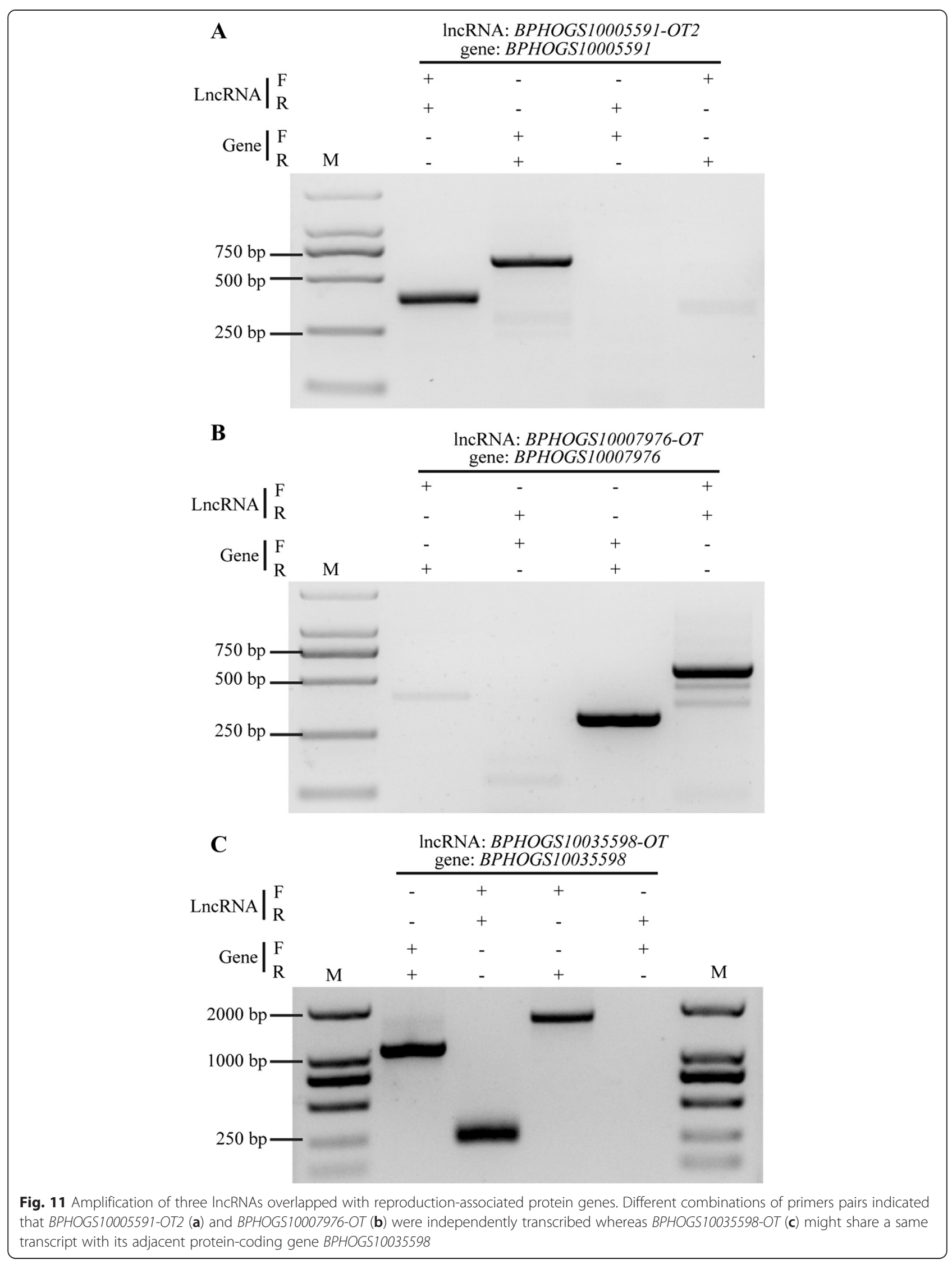


gland, and antennae of the virulence strain and three other different populations. BLASTN searching of $N$. lugens lncRNAs against the NCBI $\mathrm{nr}$ and NONCODE databases found no highly similar sequences, demonstrating that lncRNAs lack sequence conservation. However, it has been reported that an lncRNA, yar, is conserved in Drosophila species [28]. The lncRNA secondary structures of A. gambiae were conserved within the Gambiae complex [19]. Here, we found that structural features of $N$. lugens lncRNAs are similar to mammalian counterparts. We also performed RT-PCR and strandspecific PCR to confirm the expression of 20 randomly selected $\operatorname{lncRNAs}$. The results indicated that $>80 \%$ identified lncRNAs were reliable. They were unlikely to be the artifacts of full-length coding sequences.

It has been reported that the functions of lncRNAs can be inferred by analyzing their co-expression networks and genome locations $[32,33]$. In $D$. melanogaster, the IncRNA CRG positively regulates its neighboring $\mathrm{Ca}(2+)$ /calmodulindependent protein kinase, which is essential for locomotor activity and climbing ability [29]. 19-148 N. lugens lncRNAs were specifically-expressed in the HFP, LFP, TN1 and Mudgo populations, respectively. However, less than ten lncRNAs were differentially-expressed in various samples. At least three specifically-expressed lncRNAs, BPHOGS10005591OT2, BPHOGS100007976-OT, and BPHOGS10035598$O T$, overlap with reproduction-associated genes that have important functions in sperm storage and embryo dorsoventral polarity. These IncRNAs are also co-expressed with the reproduction-associated genes. According to the evidence of co-expression and genome-location, lncRNAs might have important roles in regulating fecundity in $N$. lugens. We did not find any lncRNA to be located adjacently to proteincoding genes associated with the virulence adaptation of $N$. lugens, possibly because the mechanism of virulence remains largely unknown. High fecundity and virulence adaptability are two main factors that underlie the great damage caused by $N$. lugens [31, 34]. We found indication that lncRNA might participate in the regulation of at least one of these two important biological processes, which should provide new insights into developing alternative eco-friendly pest-control policies for the rice brown planthopper. However, it should be noticed that the evidence presented here are not direct.

\section{Conclusions}

A computational pipeline was constructed to identify lncRNA genes from the rice brown planthopper, yielding 2439 IncRNA transcripts corresponding to 1882 loci. Insect lncRNAs shared similar structural gene features with mammalian lncRNAs. 19-148 lncRNAs were specificallyexpressed in high fecundity or low fecundity populations. At least three of them were overlapped with reproductive- associated genes. In terms of genome-location and geneexpression, we presented some indications that lncRNAs might play important roles in fecundity and virulence adaptation in N. lugens. Function analysis of lncRNAs is required to elucidate their roles in regulating fecundity and virulence adaptation.

\section{Methods \\ Insects}

The rice brown planthoppers were collected from rice fields in Nanjing area, Jiangsu Province, China and maintained on rice seedlings at $27 \pm 1{ }^{\circ} \mathrm{C}$, under a 16 -h light/8$\mathrm{h}$ dark photoperiod and $70-80 \%$ relative humidity. The insects were transferred to fresh seedlings every 5-7 days to ensure sufficient nutrition.

\section{Data}

The draft genome sequences of $N$. lugens were kindly provided by Professor Chuanxi Zhang in Zhejiang University [35]. We annotated the genome sequences using the OMIGA pipeline [36] and deposited the annotation information in InsectBase (http://www.insect-genome.com/). We obtained 12 transcriptomes of $N$. lugens, including transcriptome of the 5th instar nymph of a low fecundity population (LFP) and a high fecundity population (HFP), two-days old adults of LFP and HFP population and a wild population. These populations had similar genetic background because they were selected from a starting population. All insects were maintained at same conditions and the transcriptomes were sequenced with a same protocol. The detailed method procedures of sequencing the transcriptome of LFP, HFP and the control population have been reported in [37]. The other seven transcriptomes included the salivary glands of the Mudgo and TN1 population, the fat body of the Mudgo and TN1 population, the antennal of the TN1 population, I87i and C89i population. The transcriptome data were downloaded from the NCBI SRA database [38, 39]. The accession numbers were SRX276866 (the salivary glands of the Mudgo population), SRX276865 (the salivary glands of the TN1 population), SRX360414 (the fat body of the Mudgo population), SRX360412 (the fat body of the TN1 population), SRX290503 (the antennal of the TN1 population), DRX014540 (I87i strain), and DRX014541 (C89i strain).

All these transcriptomes were sequenced using the Illumina sequencing platform (GAII). Random hexamers were used in the cDNA synthesis. Total RNA were used for sequencing the transcriptomes of TN1, Mudgo, I87i and C89i populations whereas poly $(\mathrm{A})+\mathrm{RNA}$ were used for constructing the cDNA libraries in sequencing the transcriptomes of LFP, HFP and the control population. In this case, only those lncRNAs with poly (A) tails can 
be found from the transcriptomes of LFP, HFP and the control populations. It should be noted that many IncRNAs do not have poly (A) tail. These IncRNAs cannot be found from these transcriptomes.

\section{Developing a computational pipeline to identify IncRNAs}

A computational pipeline was constructed to identify lncRNA genes from the RNA-seq data. First, the RNAseq reads of $12 \mathrm{~N}$. lugens RNA-seq datasets were mapped to the genome using TopHat [40]. For the first run, the reads from each RNA-seq dataset were mapped to the genome independently. The junction outputs from each RNA-seq dataset were pooled together as a Pooled Junction Set. This allowed TopHat to use junction information from all RNA-seq datasets. For the second run, TopHat was run on each RNA-seq dataset separately using the Pooled Junction Set. The output of this second run produced the final junction set for transcript assembly using Cufflinks [3]. Second, the assembled transcripts of the 12 RNA-seq datasets were combined together by Cuffcompare, using $N$. lugens genome-annotation information. The transcripts that satisfied two criteria were retained: length $\geq 200$ nt and exon numbers $\geq 2$. This step produced 94,388 transcripts corresponding to 43,474 loci. Third, their protein coding potentials were examined by the software getorf (http://emboss.sourceforge.net/apps/cvs/emboss/apps/getorf.html). Transcripts with an open reading frame $\geq 300$ nt were removed. Fourth, the remaining transcripts were searched against the SWISS-PROT database using BLASTX. Those transcripts that had BLAST hits with known proteins $(e$-value $<0.001)$ were regarded as mRNA transcripts and removed. We also removed the putative untranslated region fragments of known mRNA transcripts by sequence alignments, producing 9392 transcripts corresponding to 6734 loci. Fifth, all 9392 transcripts were estimated by the software Coding Potential Calculator (CPC, http://cpc.cbi.pku.edu.cn/). Only those transcripts with a CPC score $\leq-1$ were kept, yielding 6175 transcripts corresponding to 4490 loci. Sixth, the remaining transcripts were used to search against the Pfam database using the software Hmmer [41]. Those transcripts that had the potential to encode conserved domains or motifs were removed. In the last step, we removed known tRNAs), ribosomal RNAs (rRNAs), snoRNA, and small nuclear RNAs (snRNAs) by searching the Rfam database using Infernal [42] and BLASTN against the NONCODE database [43], producing the final lncRNA gene sets.

\section{LncRNA gene expression analysis in $12 \mathrm{~N}$. lugens RNA-seq datasets}

The transcript abundance of the identified lncRNA genes were estimated by counting reads and normalizing with the software Cuffdiff [3], which used $T$-test to measure the significance of the expressional difference. A heatmap was produced by analyzing the expression abundance of IncRNA genes with the software Clustering [44]. The average linkage method was used and the results were viewed using Java TreeView [45]. If the expression of a lncRNA meets following criteria, we defined it as the specificallyexpressed lncRNA: 1) the expression is $>3$ FPKM in one sample whereas it is $<1$ FPKM in other samples; 2) the FPKM of this lncRNA in one sample is at least 10 -fold higher than those in other samples. For finding differentially-expressed IncRNAs, the cutoff was set as $p$-value $<0.01$ and $q$-value $<0.05 . q$-value means the FDR-adjusted $p$-value of the test statistic.

\section{Co-expression analysis of protein-coding genes and IncRNAs}

Co-expression analysis was performed between lncRNAs and protein-coding genes using all 12 transcriptome RNA-seq datasets. Pearson product-moment correlation coefficient was used to estimate the co-expression relationship by using a $\mathrm{R}$ script. The lncRNA: mRNA relationship with $|\mathrm{r}|>0.8$ were treated as the strong correlation.

\section{Structural gene features of $N$. lugens IncRNAs}

Gene structures of lncRNA genes were constructed by aligning lncRNAs with the $N$. lugens genome. The proteincoding gene information was obtained by the OMIGA annotation. The lengths of exons and introns were calculated. We wrote a Perl scalable vector graphics module to draw the exon-intron structures of the lncRNA genes. The software Geneious was used to show the transcript structure of lncRNA and protein-coding genes [46].

\section{Total RNA isolation and CDNA synthesis}

The third to the fifth instar of $N$. lugens nymph and adult were chose for gene expression analysis. Total RNA was extracted from 50 individuals of a wild population using the $\mathrm{TRIzol}^{\circ}$ reagent, following the manufacturer's instructions (Life Technologies, CA, USA). RNA integrity was checked by electrophoresis using $1.2 \%$ agarose gels. The RNA purity was examined using a Nanodrop spectrophotometer (Thermo Fisher Scientific, Waltham, MA, USA). The cDNA synthesis was performed following the manufacturer's instructions of the PrimeScript ${ }^{\mathrm{m}} \mathrm{RT}$ reagent Kit with gDNA Eraser (Takara, Kyoto, Japan). Random primers were used in the cDNA synthesis for RTPCR amplification of lncRNAs. Gene-specific primers (GSP) were used in the cDNA synthesis for the strandspecific RT-PCR.

\section{RT-PCR}

We randomly selected 20 lncRNA genes for validation. The rice brown planthoppers from a wild population were used for extracting total RNA. The strand-specific RT-PCR was used to determine the transcript orientation. In the cDNA synthesis, three reactions were used: 
Forward (F) primer with reverse transcriptase (RT), reverse $(R)$ primer with $R T$, both $F$ and $R$ primers without RT. To validate the alternative splicing of lncRNAs, we selected BPHLNC-unc241 for isoform-specific PCR. This lncRNA gene has ten alternatively spliced transcripts. The transcription of three reproduction-associated proteincoding genes (BPHOGS10005591, BPHOGS10007976 and BPHOGS10035598) and their overlapping lncRNA genes (BPHOGS10005591-OT2, BPHOGS10007976-OT and BPHOGS10035598-OT) were also confirmed by RT-PCR.

The primers were designed using an Integrated DNA Technologies online tool (IDT, Coralville, IA, USA; http:// www.idtdna.com/Scitools/) and the primer sequences are shown in Additional files 14, 15 and 16: Tables S10, S11 and S12. Premix Taq ${ }^{\circ}$ Version 2.0 kit (Takara) was used for the PCR reactions, which were performed in a T100 thermal cycler (Bio-Rad, Hercules, CA, USA). PCR conditions were $94{ }^{\circ} \mathrm{C}$ for $5 \mathrm{~min}$; followed by five cycles of $94{ }^{\circ} \mathrm{C}$ for $30 \mathrm{~s}, 60^{\circ} \mathrm{C}$ (reduced by $1{ }^{\circ} \mathrm{C} /$ cycle) for $30 \mathrm{~s}$ and $72{ }^{\circ} \mathrm{C}$ for $1 \mathrm{~min}$; and then 28 cycles of $94{ }^{\circ} \mathrm{C}$ for $30 \mathrm{~s}, 50{ }^{\circ} \mathrm{C}$ for $30 \mathrm{~s}$, and $72{ }^{\circ} \mathrm{C}$ for $1 \mathrm{~min}$. The last step was followed by final extension at $72{ }^{\circ} \mathrm{C}$ for $10 \mathrm{~min}$. The PCR products were checked by electrophoresis using $1.5 \%$ agarose gels. The PCR products were purified by using Wizard HSV Gel (Promega, Madison, WI, USA), following the manufacturer's instructions. The PCR products were sequenced by the GeneScript Company (Nanjing, China).

\section{Additional files}

Additional file 1: The sequences of identified IncRNAs in FASTA format. (FASTA $2166 \mathrm{~kb}$ )

Additional file 2: Figure S1. The relationship between the numbers of identified IncRNA genes and read counts in varied samples of N. lugens. The high coverage of RNA-seq was positively related with the numbers of detected IncRNAs. However, in the adult of HFP population, the coverage was low but a high number of IncRNAs were found. LFP: low fecundity population, HFP: high fecundity population. TN1: avirulent Taichung Native 1 host strain, Mudgo: virulent (carrying the resistance gene bph1) host strain 187i: Izumo87 strain, C89i: Chikugo89 strain. (TIFF 133 kb)

Additional file 3: Figure S2. RT-PCR validation of 20 randomly selected IncRNAs. Seventeen IncRNAs were successfully amplified and confirmed by sequencing. The PCR product in lane 15, BPHLNC-unC536, was not correctly amplified. Two InCRNAs, BPHLNC-unc525 and BPHLINC406, were not amplified and were not shown in the figure. Lane 1-18: BPHOGS10028742AS-RA, BPHLINC074-RA, BPHOGS10028378-AS-RA, BPHOGS10006054-OT-RA, BPHLINC250-RA, BPHOGS10022296-OT-RA, BPHLNC-UnC280-RA, BPHLINC164-RA BPHOGS10026274-IT-RA, BPHOGS10006052-AS-RA, BPHOGS10017161-OT-RA, BPHOGS10027736-OT-RB, BPHOGS10003291-OT-RA, BPHLNC-unc005-RA BPHLNC-UnC536-RA, BPHOGS10000919-OT-RA, BPHOGS10035448-AS-RA, BPHOGS10030139-OT-RA, respectively. (TIFF $4040 \mathrm{~kb}$ )

Additional file 4: Figure S3. Alternative splicing of identified IncRNAs in N. lugens. Most IncRNAs had only one isoforms. Only $19.9 \%$ IncRNAs had multiple isoforms. (TIFF $63 \mathrm{~kb}$ )

Additional file 5: Table S1. The number of specifically-expressed and differentially-expressed IncRNAs in various populations (DOCX $14 \mathrm{~kb}$ )

Additional file 6: Table S2. Specifically expressed IncRNAs in the fat body of Mudgo strain of N. lugens. (XLSX $9 \mathrm{~kb}$ )
Additional file 7: Table S3. Specifically expressed IncRNAs in the fat body of TN1 strain of N. lugens. (XLSX $9 \mathrm{~kb}$ )

Additional file 8: Table S4. Specifically expressed IncRNAs in the salivary gland of Mudgo strain of N. lugens. (XLSX $10 \mathrm{~kb}$ )

Additional file 9: Table S5. Specifically expressed IncRNAs in the salivary gland of TN1 strain of N. lugens. (XLSX $10 \mathrm{~kb}$ )

Additional file 10: Table S6. Specifically expressed IncRNAs in the 5th instar nymph of HFP population (XLSX $16 \mathrm{~kb}$ )

Additional file 11: Table S7. Specifically expressed IncRNAs in the adult of LFP population. (XLSX $12 \mathrm{~kb}$ )

Additional file 12: Table S8. Specifically expressed IncRNAs in the adult of HFP population. (XLSX $15 \mathrm{~kb}$ )

Additional file 13: Table S9. Specifically expressed IncRNAs in LFP the 5th instar nymph of LFP population (XLSX $13 \mathrm{~kb}$ )

Additional file 14: Table S10. Primers used for RT-PCR and strand-specific PCR. Both two pairs of primers were used for RT-PCR validation. One pair of primers was used for strand-specific PCR for determining transcript orientations. *: the primer used for strand specific PCRs. (DOCX $24 \mathrm{~kb}$ )

Additional file 15: Table S11. Primers used for RT-PCR validation of alternatively spliced isoforms of BPHLNC-unc241. (DOCX $13 \mathrm{~kb}$ )

Additional file 16: Table S12. Primers used for RT-PCR validation of three IncRNA genes and their overlapping protein coding genes. (DOCX $12 \mathrm{~kb})$

\section{Competing interests}

The authors declare that they have no competing interests.

\section{Authors' contributions}

FL conceived and designed the study. HMX conducted the study. ZTY and $\mathrm{BFH}$ helped with the validation experiment. DHG and $\mathrm{CLY}$ joined the discussion and made the figures. WQZ provided the transcriptome data. FL and HMX wrote the manuscript. All authors reviewed the manuscript. All authors read approved the final manuscript

Authors' information

Not applicable.

Availability of data and materials

Not applicable.

\section{Acknowledgments}

This work was supported by National Basic Research Program of China (2012CB114102).

\section{Author details}

'Department of Entomology, College of Plant protection, Nanjing Agricultural University, Nanjing 210095, China. ${ }^{2}$ Department of City Construction, Shaoyang University, Shaoyang 422000, China. ${ }^{3}$ State Key Laboratory for Biocontrol/Institute of Entomology, Sun Yat Sen University, Guangzhou 510275, China. ${ }^{4}$ Ministry of Agriculture Key Lab of Agricultural Entomology, Institute of Insect Sciences, Zhejiang University, 866 Yuhangtang Road, Hangzhou 310058, China.

Received: 14 June 2015 Accepted: 23 September 2015

Published online: 05 October 2015

\section{References}

1. Coordinators NR. Database resources of the National Center for Biotechnology Information. Nucleic Acids Res. 2015;43(Database issue):D6-17.

2. Kodama $Y$, Shumway M, Leinonen R, International Nucleotide Sequence Database C. The Sequence Read Archive: explosive growth of sequencing data. Nucleic Acids Res. 2012;40(Database issue):D54-6.

3. Trapnell C, Roberts A, Goff L, Pertea G, Kim D, Kelley DR, et al. Differential gene and transcript expression analysis of RNA-seq experiments with TopHat and Cufflinks. Nat Protoc. 2012;7(3):562-78.

4. Yang L, Froberg JE, Lee JT. Long noncoding RNAs: fresh perspectives into the RNA world. Trends Biochem Sci. 2014;39(1):35-43. 
5. Wilusz JE, Sunwoo H, Spector DL. Long noncoding RNAs: functional surprises from the RNA world. Genes Dev. 2009;23(13):1494-504.

6. St Laurent G, Wahlestedt C, Kapranov P. The Landscape of long noncoding RNA classification. Trends Genet. 2015;31(5):239-51.

7. Wright MW. A short guide to long non-coding RNA gene nomenclature. Hum Genomics. 2014:8:7.

8. Jia H, Osak M, Bogu GK, Stanton LW, Johnson R, Lipovich L. Genome-wide computational identification and manual annotation of human long noncoding RNA genes. RNA. 2010;16(8):1478-87.

9. Lee $T L$, Xiao A, Rennert OM. Identification of novel long noncoding RNA transcripts in male germ cells. Methods Mol Biol. 2012;825:105-14.

10. Li T, Wang S, Wu R, Zhou X, Zhu D, Zhang Y. Identification of long nonprotein coding RNAs in chicken skeletal muscle using next generation sequencing. Genomics. 2012;99(5):292-8.

11. Sun $K$, Chen $X$, Jiang $P$, Song $X$, Wang $H$, Sun $H$. iSeeRNA: identification of long intergenic non-coding RNA transcripts from transcriptome sequencing data. BMC Genomics. 2013;14 Suppl 2:S7.

12. Jalali S, Kapoor S, Sivadas A, Bhartiya D, Scaria V. Computational approaches towards understanding human long non-coding RNA biology. Bioinformatics. 2015;31(14):2241-51.

13. Cabili MN, Trapnell C, Goff L, Koziol M, Tazon-Vega B, Regev A, et al. Integrative annotation of human large intergenic noncoding RNAs reveals global properties and specific subclasses. Genes Dev. 2011;25(18):1915-27.

14. Derrien T, Johnson R, Bussotti G, Tanzer A, Djebali S, Tilgner H, et al. The GENCODE v7 catalog of human long noncoding RNAs: analysis of their gene structure, evolution, and expression. Genome Res. 2012;22(9):1775-89.

15. Xing D, Liang JQ, Li Y, Lu J, Jia HB, Xu LY, et al. Identification of long noncoding RNA associated with osteoarthritis in humans. Orthop Surg. 2014;6(4):288-93.

16. Ganegoda GU, Li M, Wang W, Feng Q. Heterogeneous network model to infer human disease-long intergenic non-coding RNA associations. IEEE Trans Nanobioscience. 2015:14(2):175-83.

17. Xue Y, Ma G, Gu D, Zhu L, Hua Q, Du M, et al. Genome-wide analysis of long noncoding RNA signature in human colorectal cancer. Gene. 2015;556(2):227-34.

18. Zhou ZY, Li AM, Adeola AC, Liu YH, Irwin DM, Xie HB, et al. Genome-wide identification of long intergenic noncoding RNA genes and their potential association with domestication in pigs. Genome Biol Evol. 2014;6(6):1387-92.

19. Jenkins AM, Waterhouse RM, Muskavitch MA. Long non-coding RNA discovery across the genus anopheles reveals conserved secondary structures within and beyond the Gambiae complex. BMC Genomics. 2015:16(1):337.

20. Sytnikova YA, Rahman R, Chirn GW, Clark JP, Lau NC. Transposable element dynamics and PIWI regulation impacts IncRNA and gene expression diversity in Drosophila ovarian cell cultures. Genome Res. 2014;24(12):1977-90.

21. Brown JB, Boley N, Eisman R, May GE, Stoiber MH, Duff MO, et al. Diversity and dynamics of the Drosophila transcriptome. Nature. 2014;512(7515):393-9.

22. Young RS, Marques AC, Tibbit C, Haerty W, Bassett AR, Liu JL, et al. Identification and properties of 1,119 candidate lincRNA loci in the Drosophila melanogaster genome. Genome Biol Evol. 2012;4(4):427-42.

23. Guttman M, Donaghey J, Carey BW, Garber M, Grenier JK, Munson G, et al. lincRNAs act in the circuitry controlling pluripotency and differentiation. Nature. 2011;477(7364):295-300.

24. Kurokawa R. Long noncoding RNA as a regulator for transcription. Prog Mol Subcell Biol. 2011:51:29-41.

25. Spadaro PA, Flavell CR, Widagdo J, Ratnu VS, Troup M, Ragan C, et al. Long Noncoding RNA-Directed Epigenetic Regulation of Gene Expression Is Associated with Anxiety-like Behavior in Mice. Biol Psychiatry. 2015. doi:10.1016/j.biopsych.2015.02.004.

26. Pedrazzini T. [In the heart of noncoding RNA: a long way to go]. Med Sci (Paris). 2015;31(3):261-7.

27. Payer B, Lee JT. X chromosome dosage compensation: how mammals keep the balance. Annu Rev Genet. 2008;42:733-72.

28. Soshnev AA, Ishimoto H, McAllister BF, Li X, Wehling MD, Kitamoto T, et al. A conserved long noncoding RNA affects sleep behavior in Drosophila. Genetics. 2011;189(2):455-68.

29. Li M, Wen S, Guo X, Bai B, Gong Z, Liu X, et al. The novel long non-coding RNA CRG regulates Drosophila locomotor behavior. Nucleic Acids Res. 2012;40(22):11714-27.
30. Xu HJ, Xue J, Lu B, Zhang XC, Zhuo JC, He SF, et al. Two insulin receptors determine alternative wing morphs in planthoppers. Nature. 2015;519(7544):464-7.

31. Chen YH, Bernal CC, Tan J, Horgan FG, Fitzgerald MA. Planthopper "adaptation" to resistant rice varieties: changes in amino acid composition over time. J Insect Physiol. 2011;57(10):1375-84.

32. Liao Q, Liu C, Yuan X, Kang S, Miao R, Xiao H, et al. Large-scale prediction of long non-coding RNA functions in a coding-non-coding gene co-expression network. Nucleic Acids Res. 2011;39(9):3864-78.

33. Hao Y, Wu W, Shi F, Dalmolin RJ, Yan M, Tian F, et al. Prediction of long noncoding RNA functions with co-expression network in esophageal squamous cell carcinoma. BMC Cancer. 2015;15:168.

34. Jing $S$, Zhang L, Ma Y, Liu B, Zhao $Y, Y u$ H, et al. Genome-wide mapping of virulence in brown planthopper identifies loci that break down host plant resistance. PLoS One. 2014;9(6):e98911.

35. Xue J, Zhou X, Zhang CX, Yu LL, Fan HW, Wang Z, et al. Genomes of the rice pest brown planthopper and its endosymbionts reveal complex complementary contributions for host adaptation. Genome Biol. 2014;15(12):521.

36. Liu J, Xiao H, Huang S, Li F. OMIGA: Optimized Maker-Based Insect Genome Annotation. Mol Genet Genomics. 2014;289(4):567-73.

37. Zhai $Y$, Zhang J, Sun $Z$, Dong $X, H e ~ Y$, Kang $K$, et al. Proteomic and transcriptomic analyses of fecundity in the brown planthopper Nilaparvata lugens (Stal). J Proteome Res. 2013;12(11):5199-212.

38. Yu H, Ji R, Ye W, Chen H, Lai W, Fu Q, et al. Transcriptome analysis of fat bodies from two brown planthopper (Nilaparvata lugens) populations with different virulence levels in rice. PLoS One. 2014;9(2):e88528.

39. Ji R, Yu H, Fu Q, Chen H, Ye W, Li S, et al. Comparative transcriptome analysis of salivary glands of two populations of rice brown planthopper, Nilaparvata lugens, that differ in virulence. PLoS One. 2013;8(11):e79612.

40. Trapnell C, Pachter L, Salzberg SL. TopHat: discovering splice junctions with RNA-Seq. Bioinformatics. 2009;25(9):1105-11.

41. Finn RD, Clements J, Arndt W, Miller BL, Wheeler TJ, Schreiber F, et al. HMMER web server: 2015 update. Nucleic Acids Res. 2015;43(W1):W30-8.

42. Nawrocki EP. Annotating functional RNAs in genomes using Infernal. Methods Mol Biol. 2014;1097:163-97.

43. Xie C, Yuan J, Li H, Li M, Zhao G, Bu D, et al. NONCODEv4: exploring the world of long non-coding RNA genes. Nucleic Acids Res. 2014;42(Database issue):D98-103.

44. de Hoon MJ, Imoto S, Nolan J, Miyano S. Open source clustering software. Bioinformatics. 2004:20(9):1453-4

45. Page RD. Visualizing phylogenetic trees using TreeView. Curr Protoc Bioinformatics. 2002; Chapter 6:Unit 62.

46. Kearse M, Moir R, Wilson A, Stones-Havas S, Cheung M, Sturrock S, et al. Geneious Basic: an integrated and extendable desktop software platform for the organization and analysis of sequence data. Bioinformatics. 2012;28(12):1647-9.

\section{Submit your next manuscript to BioMed Central and take full advantage of:}

- Convenient online submission

- Thorough peer review

- No space constraints or color figure charges

- Immediate publication on acceptance

- Inclusion in PubMed, CAS, Scopus and Google Scholar

- Research which is freely available for redistribution

Submit your manuscript at www.biomedcentral.com/submit 